RESEARCH REPORT

\title{
Multiple sclerosis after infectious mononucleosis: record linkage study
}

\author{
Michael J Goldacre, Clare J Wotton, Valerie Seagroatt, David Yeates
}

J Epidemiol Community Health 2004;58:1032-1035. doi: 10.1136/jech.2003.018366

See end of article for authors' affiliations

Correspondence to Professor M J Goldacre, Unit of Health-Care, Department of Public Health, University of Oxford, Old Road, Oxford OX3 7LF, UK; michael. goldacre@dphpc.ox.ac.uk

Accepted for publictation 26 March 2004

\begin{abstract}
Objective: To ascertain if infectious mononucleosis is a risk factor for the development of multiple sclerosis (MS); and, if it is, whether its effect is close to or remote in time from the onset of MS.

Design: Analysis of database of linked abstracts of records of hospital admission and death. Setting: Health region in central southern England.

Main outcome measure: Ratio of rate of MS in a cohort of people admitted to hospital with infectious mononucleosis to the rate in a comparison cohort.

Results: Considering all time intervals from admission with infection to admission with MS, there was a non-significant increase of risk of MS in the infectious mononucleosis cohort (rate ratio 2.17, 95\% confidence intervals 0.79 to 4.77 ). At the interval of 10 years or more, there was a significant increase in risk of MS (rate ratio 4.01, 1.48 to 8.93). The mean time from infectious mononucleosis to first admission with MS was 14 years.

Conclusion: This study adds support to the evidence that Epstein-Barr virus, the cause of infectious mononucleosis, is associated with MS. Its role is probably as an initiator of the disease process of MS, or as a contributor to its early development, rather than as an activator of latent, existing disease.
\end{abstract}

M ultiple sclerosis (MS) is a disease of the central nervous system in which the myelin sheath of nerve fibres is destroyed. Its aetiology is largely unknown but an autoimmune process, after an infectious or noninfectious environmental exposure, is likely to be a contributing cause. Viral infection has long been suspected of playing a part in MS. $^{1}$ There is increasing evidence that infection with the Epstein-Barr virus (EBV) is implicated..$^{2-6}$ However, the timescale on which infection might act is still unclear. Seroepidemiological case-control studies have provided some of the most convincing evidence of a link between EBV and MS; but such studies usually cannot distinguish between recent infection or infection in the distant past. Infection could be an initiating aetiological factor, remote in time from the onset of MS; a later effect that influences the clinical manifestation of disease; or even a consequence of the onset of MS, perhaps resulting from increased susceptibility to infection.

In 2000, Ascherio and Munch undertook a systematic review of the case-control studies of EBV infection and MS. ${ }^{3}$ They identified eight studies in which EBV serology had been compared between people with MS and controls. They concluded that the consistency of association across the studies supported the likelihood that EBV plays a part in the aetiology of MS. In subsequent work, Ascherio et al and Levin et al undertook further case-control studies, nested within cohort studies that had been established for other purposes, in which serum had been stored before the onset of MS. They showed an association between EBV and MS in which EBV infection had occurred well before the onset of symptoms of MS. Marrie et al, in a case-control study, reported an increase in risk of MS in people who had evidence of EBV infection in the year before onset of MS. Lindberg et al linked data from a cohort of people with infectious mononucleosis-a common infectious disease in children, teenagers, and young adults that is caused by EBV-to a register of people with MS. Based on three cases of MS, they reported a significant increase of risk with a mean time interval of 12 years between infectious mononucleosis and MS.
We used a database of linked routine records of hospital care and of death to study the association between admission for infectious mononucleosis and subsequent MS. In particular, we wanted to discover if any association was at a long time interval from infection to MS

\section{METHODS}

\section{Population and data}

The Oxford record linkage study (ORLS) includes brief statistical abstracts of records of all hospital admissions (including day cases) in NHS hospitals, and all deaths regardless of where they occurred, in defined populations within the former Oxford NHS region, from January 11963 to March 31 1999. The hospital data were collected routinely in the NHS as the Oxford Regional Health Authority's hospital discharge statistics. The death data derive from death certificates. Data collected covered two health districts and their associated hospitals from 1963 (population 850 000), six districts from 1975 (population 1.9 million) and all districts and hospitals in the region from 1987 (population 2.5 million). The data for each person were linked together routinely as part of the region's health information system. They are anonymised and archived. The infectious mononucleosis cohort was obtained by selecting records of people less than 60 years of age admitted for infectious mononucleosis. A reference cohort was constructed by similarly selecting records of people less than 60 years of age admitted for various medical and surgical conditions. This is our "reference" group of patients that has been used in other studies of inter-relations between diseases. ${ }^{9}$ We considered that cases of MS in the reference cohort would approximate to those in the general population of the region while allowing for migration from it (data on migration of individuals were not available). This makes the assumption, which we cannot test, that out-migration from the infectious mononucleosis and reference cohorts are similar. Anyone with a reference condition and infectious

Abbreviations: MS, multiple sclerosis; EBV, Epstein-Barr virus 
Table 1 Age distribution of study population of people admitted to hospital with infectious mononucleosis: number and percentage of people in each age group at time of admission

\begin{tabular}{llr}
\hline \multirow{2}{*}{$\begin{array}{l}\text { Age group } \\
\text { (years) }\end{array}$} & \multicolumn{2}{l}{ Infectious mononucleosis } \\
\cline { 2 - 3 } & Number & $\%$ \\
\hline $0-4$ & 129 & 4.7 \\
$5-9$ & 219 & 7.9 \\
$10-14$ & 320 & 11.6 \\
$15-19$ & 1024 & 37.0 \\
$20-24$ & 570 & 20.6 \\
$25-29$ & 221 & 7.9 \\
$30-34$ & 99 & 3.6 \\
$35-39$ & 68 & 2.5 \\
$40-44$ & 43 & 1.6 \\
$45-49$ & 33 & 1.2 \\
$50-54$ & 18 & 0.6 \\
$55-59$ & 23 & 0.8 \\
Total & 2767 & 100.0 \\
\hline
\end{tabular}

mononucleosis was entered into the "infectious mononucleosis" cohort from the time of admission with infectious mononucleosis. We searched the database for any subsequent record of MS in the infectious mononucleosis cohort and the reference cohort.

\section{Statistical methods}

We calculated standardised rates of subsequent MS in each cohort-the infectious mononucleosis and reference cohortbased on person years at risk. We took "date of entry" into each cohort as date of first admission for infectious mononucleosis or reference condition and "date of exit" as the date of subsequent admission for MS if it occurred, death, or 31 March, 1999, whichever was the earliest. We standardised by age (in five year age groups), sex, calendar year of first recorded admission (in single years), and district of residence. The combined infectious mononucleosis and reference cohorts were used as the standard population (that is, we used internal standardisation). We did the standardisation by calculating, within each age-sex-year-district stratum, the rate of MS per person years at risk in the standard population; and by applying this rate to the person years at risk in each equivalent stratum in each individual infectious mononucleosis and reference cohort. This gave us an expected number in each stratum in each cohort. For each cohort, we then summed the expected numbers across all the strata, and compared the summed expected with the summed observed number. We expressed these as an overall standardised rate, for each cohort, by adjusting the ratio of observed to expected numbers by the crude rate of MS in the standard population. We then calculated the ratio of the standardised rate of occurrence in the infectious mononucleosis cohort relative to that in the reference cohort. The confidence interval for the rate ratio and $\chi^{2}$ statistics for its significance were calculated as described elsewhere. ${ }^{10}$

Each five year age group of infectious mononucleosis patients was compared with as many people with the reference conditions as there were on file in each age group. We did this to increase the precision of our estimates. We divided time intervals from infection to outcome into less than 1 year apart, $1-4,5-9$, and 10 years or more apart.

\section{RESULTS}

There were 2767 patients in the infectious mononucleosis cohort. Their mean age at first admission was 18 years and the average length of follow up was 15.3 years. Table 1 shows the age distribution of the infectious mononucleosis patients at the time of first admission. Sixty per cent were under 20 years of age at the time of first recorded admission. There were 640163 people in the reference cohort with a mean number of 53347 in each five year age stratum (range 32205 to 83436 people in each stratum).

Overall, our results showed a non-significant association between infectious mononucleosis and subsequent MS (rate ratio $2.2 ; 95 \%$ confidence intervals 0.8 to 4.8 (table 2 ). However, all six cases of infectious mononucleosis followed by MS occurred 10 or more years after admission for infectious mononucleosis and, at that time interval, this gave a ratio that was significantly high (rate ratio 4.0; $95 \%$ confidence intervals 1.5 to 8.9 ). We inspected the results for each individual condition in the reference cohort as well as for the cohort as a whole. We did this to ensure that no individual condition had an undue influence on the overall result. It did not; and, in particular, the group of upper respiratory diseases showed no association with subsequent MS.

Table 2 Number of people in the infectious mononucleosis cohort with MS ("observed number"), expected number, ratio of rates in the infectious mononucleosis cohort to those in the reference cohort, and $95 \%$ confidence intervals for the rate ratio

\begin{tabular}{|c|c|c|c|c|}
\hline Virus infection & $\begin{array}{l}\text { Observed number } \\
\text { of MS in infectious } \\
\text { mononucleosis } \\
\text { cohort }\end{array}$ & $\begin{array}{l}\text { Expected } \\
\text { number of MS } \\
\text { in infectious } \\
\text { mononucleosis } \\
\text { cohort* }^{*}\end{array}$ & $\begin{array}{l}\text { Adjusted } \\
\text { rate ratiot }\end{array}$ & $\begin{array}{l}95 \% \\
\text { Confidence } \\
\text { intervals }\end{array}$ \\
\hline \multicolumn{5}{|l|}{ Multiple sclerosis after: } \\
\hline Infectious mononucleosis-all intervals & 6 & 2.8 & 2.17 & 0.79 to 4.77 \\
\hline$<1$ year & 0 & 0.1 & 0.00 & 0 to 25.4 \\
\hline $1-4$ years & 0 & 0.6 & 0.00 & 0 to 6.30 \\
\hline $5-9$ years & 0 & 0.6 & 0.00 & 0 to 6.73 \\
\hline $10+$ years & 6 & 1.5 & 4.01 & 1.48 to 8.93 \\
\hline
\end{tabular}

ICD codes for infectious mononucleosis: ICD7 093, ICD8 075, ICD9 075, ICD10 B27. ICD codes for multiple sclerosis: ICD7 345, ICD8 340, ICD9 340, ICD10 G35. Conditions used in reference cohort, with Office of Population, Censuses and Surveys code edition 4 for operations and ICD9 code for diagnosis (with equivalent codes used for other coding editions): appendicectomy (OPCS 441-444), tonsillectomy/adenoidectomy (230236), squint (ICD9 378), otitis externa, otitis media (380-382), varicose veins (454), upper respiratory infections (460-466), deflected nasal septum, nasal polyp (470-471), impacted tooth and other disorders of teeth (520521), inguinal hernia (550), ingrowing toenail and other diseases of nail (703), sebaceous cyst (706.2), internal derangement of knee (717), bunion (727.1), limb fracture (810-816, 823-826), dislocations, sprains and strains (830-839, 840-848), superficial injury and contusion (910-919, 920-924). *Based on the rates in the infectious mononucleosis cohort and reference cohort combined. †Adjusted for sex, age in five year bands, district of residence, and time period in single calendar years. 


\section{Key points}

- The aetiology of multiple sclerosis (MS) is largely unknown but there is increasing evidence that infection with Epstein-Barr virus, which causes infectious mononucleosis, may be implicated.

- The timescale on which infection might act is unclear: infection could be an initiating factor for MS, remote in time before it, or a later factor that precipitates manifestation of disease.

- We used a database of linked hospital records to discover if infectious mononucleosis is followed by MS more often than expected by chance.

- We found a significant increase in MS 10 years and more after infectious mononucleosis: the mean period from infectious mononucleosis to first recorded admission with MS was 14 years.

- Infectious mononucleosis probably contributes to the initiation of MS.

The mean age at admission for infectious mononucleosis of the six people who subsequently developed MS was 17 years (range 12 to 22 ). The mean time period from infectious mononucleosis to first recorded admission for MS was 14 years (range 11 to 18 years).

\section{DISCUSSION}

It is probable that several factors interact to cause MS. In susceptible people, an initiating event is followed by a response that leads to the destruction of myelin. Susceptibility may include not only genetic predisposition ${ }^{11}$ but also dietary and nutritional factors. ${ }^{12}$ The response to initiating events may be influenced by environmental factors-in particular, the latitude related distribution of MS may be a consequence of the protective effect of solar radiation on the development of MS. ${ }^{13}{ }^{14}$ The lack of winter sunshine in countries far from the equator may reduce vitamin D production; and there is evidence that vitamin D may be an inhibitor of processes that lead to MS. ${ }^{15}$

In recent years evidence has accumulated that EBV infection also plays a part in the causal network of development of MS. In attempting to find out whether EBV infection is an initiating event in the development of MS in some people, our analysis has the strength that the temporal relation between infection and MS can be studied. Furthermore, unlike case control studies based on recall of infections in the distant past, it is not dependent on the accuracy of memory. A limitation is that it is confined to patients whose infection was serious enough to lead to hospital care. Infection with EBV is common; and it uncommonly leads to hospital admission. This means that our study design is very dilute, in the following sense: it is a comparison between one group of people, all of whom had infectious mononucleosis, and another, the reference cohort, some of whom will have had EBV infection without hospital admission. As others have commented, the high prevalence of EBV infection in people without MS is a problem for most epidemiological study designs of EBV and MS. ${ }^{3}$

Because our study is restricted to patients who were admitted to NHS hospitals, the question arises of whether factors that influenced the likelihood of admission might have biased our results. One reason for stratifying the cohorts for district of residence and year of admission was that both factors may be associated with clinical thresholds for admission to hospital. We therefore stratified by these
Policy implication

Infection with Epstein-Barr virus, the cause of infectious mononucleosis, is probably one of the causes of multiple sclerosis.

variables to make the infectious mononucleosis and reference cohorts equivalent in these respects. There is no routine collection of clinical data on outpatients in England and therefore no data exist on the percentage of people with infectious mononucleosis who are treated as outpatients and inpatients. There are also no routinely available clinical data on use of the private sector for hospital care. Private expenditure figures on health care are available for the United Kingdom as a whole. They show that private expenditure, as a percentage of all healthcare expenditure, has increased from 3.5\% in 1973 (the earliest available data) to $8.5 \%$ in $1998 .^{16}$ Thus, the use of private hospital care is small and, furthermore, it is predominantly used for elective surgery rather than acute medical care. We doubt that many people acutely ill enough to require hospital care for infectious mononucleosis would have been admitted to private rather than NHS hospitals in the period covered by the study. We also think that most patients with MS would have been admitted for NHS care on at least one occasion. Although there has probably been a tendency towards ambulatory rather than hospital care for MS patients recently, the decision on whether or not to admit MS patients is unlikely to have been influenced by whether they had had an admission for infectious mononucleosis many years previously.

There are two published studies that used similar designs to ours. The study by Lindberg et al used a cohort of records of infectious mononucleosis linked to records of MS. ${ }^{8}$ They reported a significant association between infectious mononucleosis and MS, based on three cases of MS in the cohort, with a long time interval between the two conditions. Marrie et al undertook a case-control study, of MS and controls, using a dataset of computerised general practice records with a more limited timeframe. ${ }^{7}$ They found a significant association between the conditions, based on five cases of infectious mononucleosis among the cases of MS, with a year or less between the two conditions. Our study, too, is based on small numbers of people with both infectious mononucleosis and MS. However, studies of similar design could be performed using other longstanding linked databases-for example, in the Scandinavian countries, Scotland and Western Australia ${ }^{17}{ }^{18}$ - to increase numbers on which to base firm conclusions.

In conclusion, we found a significant association between infectious mononucleosis and MS 10 years and more apart. The mean interval from infectious mononucleosis to MS was 14 years. This compares with the interval of 12 years reported by Lindberg et al. Our findings add epidemiological evidence to the likelihood that EBV is a cause of MS in some people. They also add to the evidence that the effect of EBV infection is remote in time. ${ }^{5}$ This being so, it suggests that EBV infection is probably an initiator of MS rather than an activator of clinical manifestations of latent disease.

\section{ACKNOWLEDGEMENTS}

The database was funded by the former Oxford Regional Health Authority and, over many years, it was built by Leicester Gill and Glenys Bettley. The Research and Development Directorate at the Department of Health funds the Unit of Health Care Epidemiology to undertake research using the database. We thank Sir Donald 
Acheson for helpful discussions. Sir Donald founded the Oxford record linkage study and directed it from 1963-68.

\section{Authors' affiliations}

M J Goldacre, C J Wotton, V Seagroatt, D Yeates, Unit of Health-Care Epidemiology, Department of Public Health, University of Oxford, Oxford, UK

Conflicts of interest: none declared.

\section{REFERENCES}

1 Dean G. Annual incidence, prevalence, and mortality of multiple sclerosis in white South-African-born and in white immigrants to South Africa. BMJ 1967;ii:724-30.

2 Warner HB, Camp RI. Multiple sclerosis and Epstein-Barr virus. Lancet $1981 ;$;i: 1290.

3 Ascherio A, Munch M. Epstein-Barr virus and multiple sclerosis. Epidemiology 2000;1 1:220-4.

4 Ascherio A, Munger KL, Lennette ET, et al. Epstein-Barr virus antibodies and risk of multiple sclerosis (a prospective study). JAMA 2001;286:3083-8.

5 Levin LI, Munger KL, Rubertone MV, et al. Multiple sclerosis and Epstein-Barr virus. JAMA 2003;289:1533-6.

6 Wandinger K, Jabs W, Siekhaus A, et al. Association between clinical disease activity and Epstein-Barr virus reactivation in MS. Neurology 2000;55:178-84.

7 Marrie RA, Wolfson C, Sturkenboom MC, et al. Multiple sclerosis and antecedent infections: a case-control study. Neurology 2000;54:2307-10.
8 Lindberg C, Andersen O, Vahlne A, et al. Epidemiological investigation of the association between infectious mononucleosis and multiple sclerosis. Neuroepidemiology 1991;10:62-5.

9 Goldacre M, Kurina L, Yeates D, et al. Use of large medical databases to study associations between diseases. Q J Med 2000:93:669-75.

10 Breslow NE, Day NE. Statistical methods in cancer research, Volume 11. The design and analysis of cohort studies. IARC scientific publication no 82. Lyon: International Agency for Research in Cancer, 1987:103-5.

11 Jersild C, Grunnet N. Demyelinating disease. In: King RA, Rotter Jl, Motulsky AG, eds. The genetic basis of common diseases. Oxford: Oxford University Press, 1992:753-74.

12 Ben-Shlomo Y, Davey Smith G, Marmot MG. Dietary fat in the epidemiology of multiple sclerosis: has the situation been adequately assessed? Neuroepidemiology 1992;11:214-25.

13 van der Mei IAF, Ponsonby A-L, Dwyer T, et al. Past exposure to sun, skin phenotype, and risk of multiple sclerosis: case-control study. BMJ 2003;327:316-19.

14 Goldacre MJ, Seagroatt $V$, Yeates D, et al. Skin cancer in people with multiple sclerosis: a record linkage study. J Epidemiol Community Health 2004;58: 142-4.

15 Hayes CE. Vitamin D: a natural inhibitor of multiple sclerosis. Proc Nutr Soc 2000;59:531-5.

16 Yuen P. Office of Health Economics compendium of health statistics. London: Office of Health Economics 2002, section 2, 1-7.

17 Kendrick S, Clarke J. The Scottish record linkage system. Health Bull 1993;51:72-9.

18 Holman CD, Bass AJ, Rouse IL. et al. Population-based linkage of health records in Western Australia: development of a health services research linked database, Australian and New Zealand Journal of Public Health, 1999;23:453-9.

\section{APHORISM OF THE MONTH}

\section{"If you always do what you always did, you always get what you always got."} (Anon)

$\mathrm{O}$ ne of the defining characteristics of human beings is held to be their capacity to learn from experience, yet how often is the response to delivery failure to increase the exhortation just to do better or work smarter, rather than think of another way of tackling the issue? Even the current fashion for scenario planning tends to reinforce this. It is customary to have three scenarios:

- business as usual

- smart working with performance management

- doing things differently

The problem is that, like circus animals trained to jump through hoops, health planners and managers don't know what they don't know, and may have a limited repertoire of response to complex problems. The only way to break new ground in to lateral problem solving is by creating environments that embrace diverse analysis, ideas, and experiences. 